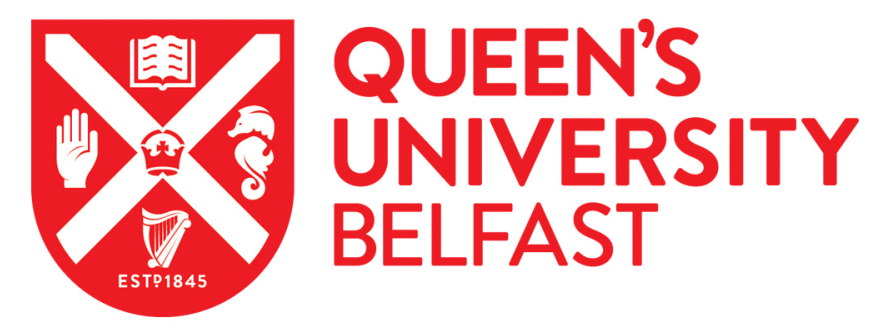

\title{
Sonochemical synthesis and measurement of optical properties of zinc sulfide quantum dots
}

Goharshadi, E. K., Sajjadi, S. H., Mehrkhah, R., \& Nancarrow, P. (2012). Sonochemical synthesis and measurement of optical properties of zinc sulfide quantum dots. Chemical Engineering Journal, 209, 113-117. https://doi.org/10.1016/j.cej.2012.07.131

\section{Published in:}

Chemical Engineering Journal

\section{Document Version:}

Peer reviewed version

Queen's University Belfast - Research Portal:

Link to publication record in Queen's University Belfast Research Portal

\section{Publisher rights}

(c) 2012. This manuscript version is made available under the CC-BY-NC-ND 4.0 license http://creativecommons.org/licenses/by-nc-nd/4.0/ which permits distribution and reproduction for non-commercial purposes, provided the author and source are cited.

\section{General rights}

Copyright for the publications made accessible via the Queen's University Belfast Research Portal is retained by the author(s) and / or other copyright owners and it is a condition of accessing these publications that users recognise and abide by the legal requirements associated with these rights.

Take down policy

The Research Portal is Queen's institutional repository that provides access to Queen's research output. Every effort has been made to ensure that content in the Research Portal does not infringe any person's rights, or applicable UK laws. If you discover content in the Research Portal that you believe breaches copyright or violates any law, please contact openaccess@qub.ac.uk. 


\section{Accepted Manuscript}

Sonochemical synthesis and measurement of optical properties of zinc sulfide quantum dots

Elaheh K. Goharshadi, Sayyed Hashem Sajjadi, Roya Mehrkhah, Paul Nancarrow

PII:

S1385-8947(12)01033-9

DOI: http://dx.doi.org/10.1016/j.cej.2012.07.131

Reference: CEJ 9646

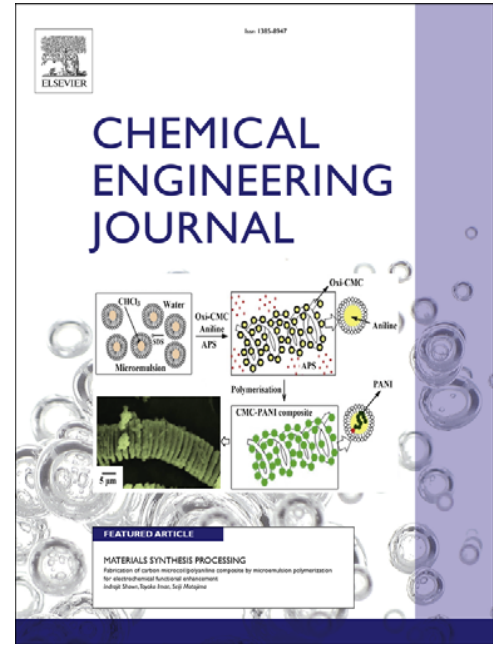

To appear in:

Chemical Engineering Journal

Received Date:

2 May 2012

Revised Date:

15 July 2012

Accepted Date:

27 July 2012

Please cite this article as: E.K. Goharshadi, S.H. Sajjadi, R. Mehrkhah, P. Nancarrow, Sonochemical synthesis and measurement of optical properties of zinc sulfide quantum dots, Chemical Engineering Journal (2012), doi: http:// dx.doi.org/10.1016/j.cej.2012.07.131

This is a PDF file of an unedited manuscript that has been accepted for publication. As a service to our customers we are providing this early version of the manuscript. The manuscript will undergo copyediting, typesetting, and review of the resulting proof before it is published in its final form. Please note that during the production process errors may be discovered which could affect the content, and all legal disclaimers that apply to the journal pertain. 
P. S. All in red should be addaed.

Sonochemical synthesis and measurement of optical properties of zinc sulfide

quantum dots

Elaheh K. Goharshadi ${ }^{\mathrm{a}, \mathrm{b}, *}$, Sayyed Hashem Sajjadi ${ }^{\mathrm{c}}$, Roya Mehrkhah ${ }^{\mathrm{a}}$, and Paul Nancarrow ${ }^{\mathrm{d}}$

${ }^{a}$ Department of Chemistry, Faculty of Sciences, Ferdowsi University of Mashhad, Mashhad 917751436, Iran

${ }^{\mathrm{b}}$ Center of Nano Research, Ferdowsi University of Mashhad, Mashhad 91775-1436, Iran

${ }^{\mathrm{c}}$ Department of Chemistry, Sharif University of Technology, Tehran, Iran

${ }^{\mathrm{d}}$ School of Chemistry and Chemical Engineering, Queen's University Belfast, UK

* To whom correspondence should be addressed. E-mail: gohari@ferdowsi.um.ac.ir. Tel: +98-511-8797022 (Ext. 308). Fax:+98-511-8796416. 


\begin{abstract}
A facile sonochemical method has been developed to prepare very small zinc sulfide nanoparticles ( $\mathrm{ZnS}$ NPs) of extremely small size about $1 \mathrm{~nm}$ in diameter using a set of ionic liquids based on the bis (trifluoromethylsulfonyl) imide anion and different cations of 1-alkyl-3-methyl-imidazolium. The structural features and optical properties of the NPs were determined in depth with X-ray powder diffraction (XRD), transmission electron microscopy (TEM), high-resolution TEM (HRTEM), Fourier transform infrared (FTIR) spectroscopy, dynamic light scattering (DLS) analysis, and UV-vis absorption spectroscopy. The energy band gap measurements of ZnS NPs were calculated by UV-vis absorption spectroscopy. One of the interesting features of the present work is that the wide band gap semiconductor $\mathrm{ZnS}$ nanocrystals were prepared which are used in the fabrication of photonic devices.
\end{abstract}

Keywords: Zinc sulfide nanoparticles; ionic liquid; sonochemical method; optical properties; band gap 


\section{Introduction}

Semiconductor nanomaterials exhibit unique size-dependent physical and chemical properties that differ from those of the bulk systems [1]. Among them, zinc sulfide, $\mathrm{ZnS}$, has attracted much research interest because of its excellent properties and applications in laser devices [2], mesoscopic electronic and optical devices [3], light-emitting diode (LED), thin film solar cells, IR windows [4], etc. Many methods have been developed for the preparation of ZnS NPs including solid-phase reactions [5], sol-gel process [6], solvothermal route [7,8], sonochemical method [9,10], liquid-phase chemical precipitation [11], ion complex transformation method [12], and microwave irradiation [13].

Sonochemistry has been used successfully to prepare NPs because this method can produce particles with much smaller size and higher surface area than those reported by other methods [14]. The chemical effects of powerful ultrasound arise from acoustic cavitations which are the formation, growth, and implosive collapse of bubbles in a liquid [15].

Room-temperature ionic liquids (ILs) are attractive environmentally benign solvents for organic chemical reactions, separations, and electrochemical applications [16]. Ionic liquids are favorable media for the electrostatic stabilization of preformed NPs at room temperature [17-19].

In this work, we applied ultrasound irradiation in conjunction with the set of ionic liquids based on the bis (trifluoromethylsulfonyl) imide anion and different cations of 1-alkyl-3-methyl-imidazolium to produce ZnS NPs of extremely small size about $1 \mathrm{~nm}$ in diameter without using surfactant.

The structural and optical properties of the NPs were determined with XRD, TEM, HRTEM, FTIR spectroscopy, DLS analysis, and UV-vis absorption spectroscopy. The energy band gap measurements of ZnS NPs were carried out by UV-visible absorption spectroscopy. To the best of our knowledge, for the first time, these ionic liquids are used for the synthesis of ZnS NPs. 


\section{Experimental}

\subsection{Materials}

All ILs, namely 1-butyl-3-methylimidazolium bis (trifluoromethylsulfonyl) imide $\left(\left[\mathrm{C}_{4} \mathrm{mim}\right]\left[\mathrm{NTf}_{2}\right]\right)$, 1-hexyl-3-methylimidazolium bis (trifluoromethylsulfonyl) imide $\left(\left[\mathrm{C}_{6} \mathrm{mim}\right]\left[\mathrm{NTf}_{2}\right]\right.$ ), and 1-octyl-3methylimidazolium bis (trifluoromethylsulfonyl) imide $\left(\left[\mathrm{C}_{8} \mathrm{mim}\right]\left[\mathrm{NTf}_{2}\right]\right)$ used in this work were synthesized according to the literature [20]. All ionic liquids were analyzed by NMR, Karl-Fischer titration for water content, and ion chromatography for chloride content. In all cases, the water mass fraction was found to be less than 0.001 and chloride mass fraction was less than $5 \times 10^{-6}$. All other chemicals used were of analytical grade and used as received without further purification.

\subsection{Preparation}

In a typical synthesis of $\mathrm{ZnS}$ NPs, 12 gram zinc acetate $\left(\mathrm{Zn}\left(\mathrm{CH}_{3} \mathrm{COO}\right)_{2} \cdot 2 \mathrm{H}_{2} \mathrm{O}\right)$ was dissolved in 100 $\mathrm{ml}$ deionized water. To this soluition, $2 \mathrm{ml}$ ionic liquid and 3.7 gram thioacetamide $\left(\mathrm{CH}_{3} \mathrm{CSNH}_{2}\right)$ were added. The solution was kept in ambient environment with a stirring rate $500 \mathrm{rpm}$ for $20 \mathrm{~min}$. Then, the reaction ultrasonicated using Sonicator $4000(20 \mathrm{kHz})$ for $1 \mathrm{~h}$. The temperature was maintained $15{ }^{\circ} \mathrm{C}$ by a water jacket. The total acoustic power injected into the sample solution was found to be $44 \pm 0.5 \mathrm{~W}$ by calorimetry. When the reaction was finished, a white precipitate was obtained. The resulting precipitate was centrifuged $(15000 \mathrm{rpm})$ and washed with ethanol and deionized water several times to remove excess ILs and any possible ionic remnants. At last, the products were dried in a vacuum oven at $60{ }^{\circ} \mathrm{C}$ for 15 hours. A similar procedure was used for the fabrication of ZnS NPs in the absence of ILs.

To understand the role of ultrasound in the preparation, ZnS NPs were prepared using microwave $(1000 \mathrm{~W})$ method in the presence of $\left[\mathrm{C}_{4} \mathrm{mim}\right]\left[\mathrm{NTF}_{2}\right]$. For this purpose, all the reaction conditions were the same except microwave waves was vused instead of ultrasound waves. A working cycle of $10 \mathrm{~s}$ on and $5 \mathrm{~s}$ off (30\% power) was used. 


\subsection{Characterization}

The powder phases were determined by means of a Bruker/ D8 Advanced diffractometer in the $2 \theta$ range from $20^{\circ}$ to $70^{\circ}$, by step of 0.04 degree, with graphite monochromatic $\mathrm{Cu}$ K $\alpha$ radiation $(\lambda=1.541$ $\AA ̊$ ). The TEM images were taken by LEO 912. The HRTEM images were taken by FEI Tecnai F20 Field emission using an accelerating voltage of $200 \mathrm{kV}$.

The DLS experiments of the particles were measured by the Zetasizer (Nano-ZS) from Malvern Instrument.

The FTIR spectra of the ZnS NPs were recorded at room temperature with a $\mathrm{KBr}$ pellet on a Shimadzu 4300 Spectrometer ranging from 400 to $4000 \mathrm{~cm}^{-1}$. The UV-vis absorbance spectra were obtained for the samples using an Agilent photodiode-array Model 8453 equipped with quartz cell of 1 $\mathrm{cm}$ path length. The spectra were recorded at room temperature in air within the range 200-550 $\mathrm{nm}$.

\section{Results and discussion}

\subsection{Structure and morphology}

Fig. 1 shows the XRD patterns of the ZnS NPs. All the diffraction peaks were labeled and indexed as the cubic phase. The strong and sharp diffraction peaks indicate the good crystallinity of the samples. No additional peaks in the XRD were observed, revealing the high purity of the prepared ZnS NPs.

The average crystallite size of $\mathrm{ZnS}$ NPs, $D_{h k l}$, can be calculated using the Scherrer's equation:

$$
D_{h k l}=\frac{k \times \lambda}{\beta_{h k l} \times \cos \theta_{h k l}}
$$

where $D_{\text {hkl }}$ is the particle size perpendicular to the normal line of (hkl) plane, $k$ is a constant (0.9), $\beta_{\mathrm{hkl}}$ is the full width at half maximum of the (hkl) diffraction peak, $\theta_{\mathrm{hkl}}$ is the Bragg angle of (hkl) peak, and $\lambda$ is the wavelength of X-ray. The peak position and the FWHM were obtained by fitting the measured peaks with two Gaussian curves in order to find the true peak position and width corresponding to 


\section{ACCEPTED MANUSCRIPT}

monochromatic $\mathrm{Cu} \mathrm{K \alpha}$ radiation. The characteristics of the $\mathrm{ZnS}$ NPs from the XRD patterns were summarized in Table 1. The lattice constants of $\mathrm{ZnS}$ nanosamples derived from the XRD data exhibit a lattice contraction with respect to the value reported for bulk cubic $\mathrm{ZnS}\left(\mathrm{a}=5.41 \mathrm{~A}^{\circ}[21]\right)$. Reduction of the lattice parameters in magnitude is called the lattice contraction that has important influences on physical and chemical properties of a material. With shrinking the solid size of a material to nanoscale, the strain will be spontaneous taken place due to high ratio of surface atoms with respect to the bulk atoms and hence the lattice contraction occurs.

The average crystallite size of ZnS NPs does not change when ILs were used. However, ILs prevent the further growth of ZnS NPs. In our previous work, cerium oxide NPs were prepared by microwave in the presence of these ionic liquids [22]. The crystallite size of cerium oxide NPs changed when ILs was used. Hence, it is plausible to say that the effect of sonication is much greater than that of ILs. In fact, the ultrasonic waves cause the breakup of the agglomerates. The deagglomeration by ultrasonication is a result of ultrasonic cavitation. Ultrasonic cavitation in liquids causes high-speed liquid jets of up to $1000 \mathrm{~km} / \mathrm{hr}$. Such jets press liquid at high pressure between the particles and separate them from each other.

The TEM images of samples 1,3, and 4 were shown in Fig. 2. All the samples display uniform cubic morphology with the average particle size below $1 \mathrm{~nm}$ which are in agreement with the XRD results. The histogram of particle size distribution (PSD) for sample 1 was measured and shown in Fig. 2. Recently, Fang et al. [23 ] provided a comprehensive review of the state-of-the-art research activities related to $\mathrm{ZnS}$ nanostructures, including their synthesis, novel properties studies, and potential applications. He reviewed the various facile techniques applied for synthesis of $\mathrm{ZnS}$ NPs. None of the methods could prepare ZnS NPs with the average particle size less than $2 \mathrm{~nm}$ prepared in this work.

Fig. 2 (d) also shows the TEM image of ZnS NPs prepared by microwave method in the presence of $\left[\mathrm{C}_{4} \mathrm{mim}\right]\left[\mathrm{NTF}_{2}\right]$. All the particles display uniform cubic morphology with average size of about $6.0 \mathrm{~nm}$ 
which is more than that of sample 2 which was prepared by utrasound method. As the HRTEM image of sample 1 (Fig. 3) shows the ZnS NPs are very fine.

Figure 4 shows the FTIR spectra of the samples. The doublet around $694 \mathrm{~cm}^{-1}$ assigned to the $\mathrm{Zn}-\mathrm{S}$ stretching band confirms the formation of $\mathrm{ZnS}$ [24]. The peak at ca. $3400 \mathrm{~cm}^{-1}$ corresponds to the physically adsorbed water on the NPs.

The size distribution of the samples 1 and 4 was examined by a DLS analyzer (Fig. 5). The DLS data suggest that the samples 1 and 4 mainly consist of particles of about $11.5 \mathrm{~nm}$ and $18 \mathrm{~nm}$, respectively. Clearly, the particle size measured by DLS analysis is larger than that of the TEM analysis since the hydrodynamic radius is probed with DLS.

The optical responses of the ZnS NPs were investigated via UV-vis absorption spectroscopy and the results were presented in Fig. 6 for sample 1 and Table 2. As Table 2 shows a blue shift occurs compared with the maximum absorption peak of bulk $\mathrm{ZnS}(345 \mathrm{~nm})$. The shift of the absorption edges to shorter wavelengths is due to the quantum confinement of $\mathrm{ZnS}$ NPs.

The optical energy band gap, $E_{g}$ was been calculated from the UV-vis spectrum using the Tauc relation [25]:

$$
(\alpha h v)^{n}=B\left(h v-E_{\mathrm{g}}\right)
$$

where $h v$ is the photon energy, $\alpha$ is the absorption coefficient, $B$ is a constant relative to the material, and $n$ is either 2 for a direct transition or $1 / 2$ for an indirect transition. Since zinc sulfide is a direct band gap semiconductor, the value of $n$ is 2 . The energy intercept of a plot of $(\alpha h v)^{2}$ versus $h v$ yields $E_{\mathrm{g}}(\mathrm{see}$ inset of Fig. 6). The values of direct band gap energy of the samples were summarized in Table 2. As this table shows the values of band gap were effectively tuned by the particle size or strain induced by solid size.

Since the size-related band gap shift of semiconductor nanocrystals can be quantified, it is possible to calculate an optical particle size with the band gap shift measured from absorption spectra [26]. The relation between the particle size and effective band gap of a nanomaterial can be given by the effective mass approximation model of Brus [27]: 
$E_{g, h}=E_{g, b}+\frac{\pi h}{2 R^{2}}\left(\frac{1}{m_{e}^{*}}+\frac{1}{m_{h}^{*}}\right)-\frac{1.8 e^{2}}{\varepsilon R}$

where $E_{g, b}$ is the bulk band gap $(3.54 \mathrm{eV}), R$ is the particle radius, $m_{e}^{*}$ and $m_{h}^{*}$ are the effective masses of the electron and hole, respectively where $m_{e}^{*}=0.42 m_{o}, m_{h}^{*}=0.61 m_{o} . m_{o}$ is the mass of a free electron, and $\varepsilon$ is the bulk optical dielectric constant which is 8.76 .

\section{Conclusions}

A novel method for preparation of very small ZnS NPs using ultrasonic waves in the presence of ILs was described. Our method combines the advantages of using ultrasonic and ILs. It could be a general approach for synthesizing the ZnO NPs with high yields. The optical band gap energy of ZnS NPs was calculated using UV-vis spectroscopy. The band gap of ZnS NPs estimated from the absorption peaks is much larger than that of bulk $\mathrm{ZnS}$ due to the quantum confinement effect. One of the interesting features of the present work is that the wide band gap semiconductor $\mathrm{ZnS}$ nanocrystals were prepared which are used in the fabrication of photonic devices such as blue lasers and blue ultraviolet photodetectors, etc. The other important feature is that ZnS NPs was prepared without using surfactant.

\section{Acknowledgment}

The authors are thankful to the academy of sciences for the developing world (TWAS) for financial support (07-269 RG/CHE/AS; UNESCO FR: 3240184297) to purchase Sonicator 4000. The authors also express their gratitude to Ferdowsi University of Mashhad for support in part this project (Grant No. 15349/1). The authors wish to thank Mrs. Somayeh Laleh for taking the FTIR spectra and Mrs. Roksana Pesian for taking TEM images. 


\section{References}

[1] N. M. Huang, C. S. Kan, S. Radiman, In situ synthesis of mesoporous CdS nanoparticles in ternary cubic phase lyotropic liquid crystal, Appl. Phys. A: Mater. Sci. Process. 76 (2003) $555-559$.

[2] Y. C. Zhu, Y. Bando, D. F. Xue, D. Golberg, Nanocable-aligned ZnS tetrapod nanocrystals J. Am. Chem. Soc. 125 (2003) 16196-16197.

[3] A. P. Alivisatos, Semiconductor clusters, nanocrystals, and quantum dots, Science 271 (1996) 933-937.

[4] V. Arcoleo, M. Goffredi, V. T. Liveri, Calorimetric investigation of the formation of $\mathrm{ZnS}$ nanoparticles in w/o microemulsions, J. Therm. Anal. Calorim. 518 (1998) 125-133.

[5] C. Kaito, Y. Saito, K. Fujita, A new preparation method of ultrafine particles of metallic Sulfides, Jpn. J. Appl. Phys. 26 (1987) 1973-1975.

[6] V. Stanic, T. H. Etsell, A. C. Pierre, Sol-gel processing of ZnS, Mater. Lett. 31 (1997) 35-38.

[7] S. H. Yu, J. Yang, Y. S. Wu, Z. H. Han, Y. Xie, Y. T. Qian, Hydrothermal preparation and characterization of rod-like ultrafine powders of bismuth sulfide Mater. Res. Bull. 33 (1998) $1661-1666$.

[8] S. H. Yu, Y. T. Qian, L. Shu, Y. Xie, J. Yang, C. S. Wang, Solvent thermal synthesis and characterization of ultrafine powder of bismuth sulfide, Mater. Lett. 35 (1998) 116-119.

[9] D. Routkevitch, T. Bigioni, M. Moskovits, J. M. Xu, Electrochemical fabrication of CdS nanowire arrays in porous anodic aluminum oxide templates, J. Phys. Chem. 100 (1996) $14037-14047$.

[10] J. J. Zhu, S.W. Liu, O. Palchik, Y. Koltypin, A. Gedanken, A novel sonochemical method for the preparation of nanophasic sulfides: synthesis of $\mathrm{HgS}$ and $\mathrm{PbS}$ nanoparticles, J. Solid State Chem. 153 (2000) 342-348. 


\section{ACCEPTED MANUSCRIPT}

[11] X. F. Duan, Y. Huang, R. Agarwal, C. M. Lieber, Single-nanowire electrically driven lasers, Nature 421 (2003) 241-245.

[12] M. Bredol, J. Merichi, ZnS precipitation: morphology control, J. Mater. Sci. 33 (1998) 471476.

[13] Y. Ni, G. Yin, J. Hongb, Z. Xu, Rapid fabrication and optical properties of zinc sulfide nanocrystallines in a heterogeneous system, Mater. Res. Bull. 39 (2004) 1967-1972.

[14] S. Senthilkumaar, R. T. Selvi, Formation of hexagonal shaped wurtzite zinc sulphide nanorods, Appl. Phys. A: Mater. Sci. Process. 94 (2009) 123-129.

[15] W. B. McNamara, Y. T. Didenko, K. S. Suslick, Sonoluminescence temperatures during multi-bubble cavitation, Nature 401 (1999) 772-775.

[16] J. Dupont, R. F. de Souza, P. A. Z. Suarez, Ionic Liquid (Molten Salt) Phase Organometallic Catalysis, Chem. Rev. 102 (2002) 3667-3692.

[17] E. K. Goharshadi, Y. Ding, M. N. Jorabchi, and P. Nancarrow, Ultrasound-Assisted Green Synthesis of Nanocrystalline $\mathrm{ZnO}$ in the Ionic Liquid [hmim] [NTf2], UltrasonicsSonochemistry 16 (2009) 120-123.

[18] E. K. Goharshadi, Sara Samiee, Paul Nancarrow, Fabrication of cerium oxide nanoparticles: characterization and optical properties, J. Colloid \& Interface Sci. 356 (2011) 473-480.

[19] E. K. Goharshadi, M. Abareshi, R. Mehrkhah, S. Samiee, M. Moosavi, A.Youssefi, P. Nancarrow, Preparation, structural characterization, semiconductor and photoluminescent properties of zinc oxide nanoparticles in a phosphonium-based ionic liquid, Mater. Sci. Semiconductor Processing 14 (2011) 69-72.

[20] P. Bonhôte, A. Dias, N. Papageorgiou, K. Kalyanasundaram, M. Grätzel, Hydrophobic, Highly conductive ambient-temperature molten salts, Inorg. Chem. 35 (1996) 1168-1178. 
[21] W. Vogel, P. H. Borse, N. Deshmukh, S. K. Kulkarni, Structure and stability of monodisperse 1.4-nm ZnS particles stabilized by mercaptoethanol, Langmuir 16 (2000)20322037.

[22] E. K. Goharshadi, S. Samiee, P. Nancarrow, Fabrication of cerium oxide nanoparticles: Characterization and optical properties, J. Colloid \& Interface Sci. 356 (2011) 473-480.

[23] X. Fang, T. Zhai, U. K. Gautam, L. Li, L. Wu, Y. Bando, D. Golberg, Prog. Mater. Sci. 56 (2011) 175-287.

[24] S. S. Kawar, B. H. Pawar, Nanocrystalline grain size in ZnS thin films deposited by chemical bath technique, J. Mater. Sci.: Mater Electron 21 (2010) 906-909.

[25] J. Tauc, Amorphous and Liquid Semiconductor: Plenum Press: New York, 1974.

[26] Y. Dieckmann, H. Co“lfen, H. Hofmann, A. Petri-Fink, Particle size distribution measurements of manganese-doped ZnS nanoparticles, Anal. Chem. 81 (2009) 3889-3895.

[27] L. E. Brus, Electron-electron and electron-hole interactions in small semiconductor

crystallites: The size dependence of the lowest excited electronic state, J. Chem. Phys. 80 (1984) 4403-4409. 


\section{TABLES}

\section{Table 1}

The characteristics of the ZnS NPs from XRD patterns.

\begin{tabular}{cccccc}
\hline Sample & ILs & $\mathrm{D}_{111}(\mathrm{~nm})$ & 20 & Lattice parameter $\left(\mathrm{A}^{\mathrm{o}}\right)$ & Cell volume $\left(\mathrm{A}^{03}\right)$ \\
\hline 1 & Without ILs & 2.03 & 29.40 & 5.25 & 144.70 \\
2 & {$\left[\mathrm{C}_{4} \mathrm{mim}\right]\left[\mathrm{NTF}_{2}\right]$} & 2.13 & 29.06 & 5.30 & 148.87 \\
3 & {$\left[\mathrm{C}_{6} \mathrm{mim}\right]\left[\mathrm{NTF}_{2}\right]$} & 2.05 & 29.12 & 5.29 & 148.87 \\
4 & {$\left[\mathrm{C}_{8}\right.$ mim $]\left[\mathrm{NTF}_{2}\right]$} & 2.07 & 29.05 & 5.31 & 149.72
\end{tabular}




\section{Table 2}

The optical properties of $\mathrm{ZnS}$ NPs.

\begin{tabular}{lccc}
\hline Sample & $\lambda_{\max , \mathrm{UV}}(\mathrm{nm})$ & $\mathrm{E}_{\mathrm{g}, \mathrm{UV}}(\mathrm{eV})^{\mathrm{a}}$ & $\mathrm{d}_{\mathrm{UV}}(\mathrm{nm})^{\mathrm{b}}$ \\
\hline 1 & 202 & 5.77 & 3.31 \\
2 & 200 & 5.49 & 4.77 \\
3 & 208 & 4.86 & 5.37 \\
4 & 202 & 5.58 & 3.63 \\
\hline
\end{tabular}

${ }^{a}$ Calculated from UV-Vis spectra.

${ }^{\mathrm{b}}$ Calculated using Eq. 3. 


\section{Figure Captions}

Fig. 1. The XRD pattern of ZnS NPs for: (a) sample 1, (b) sample 2, (c) sample 3, (d) sample 4.

Fig. 2. The TEM images of ZnS NPs for: (a) sample 1 along with the historam of PSD measured from the image, (b) sample 3, (c) sample 4 (d). ZnS NPs prepared by microwave method in the presence of $\left[\mathrm{C}_{4} \operatorname{mim}\right]\left[\mathrm{NTF}_{2}\right]$.

Fig. 3. The HRTEM image of sample 1.

Fig. 4. The FT-IR spectra of ZnS NPs for: (a) sample 1, (b) sample 2, (c) sample 3, (d) sample 4.

Fig. 5. The DLS data of size distribution of (a) sample (1) and (b) sample 4.

Fig. 6. The UV-vis spectrum of sample 1 dispersed in ethanol. Plot of ( $\alpha h v)^{2}$ vs. photon energy (inset). 


\section{FIGURES}

Fig. 1

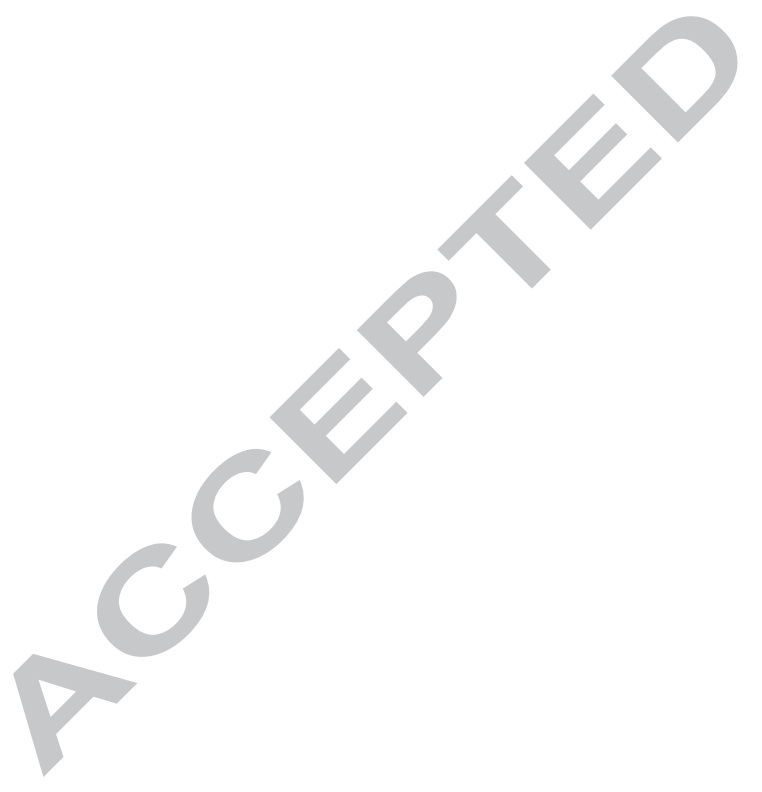




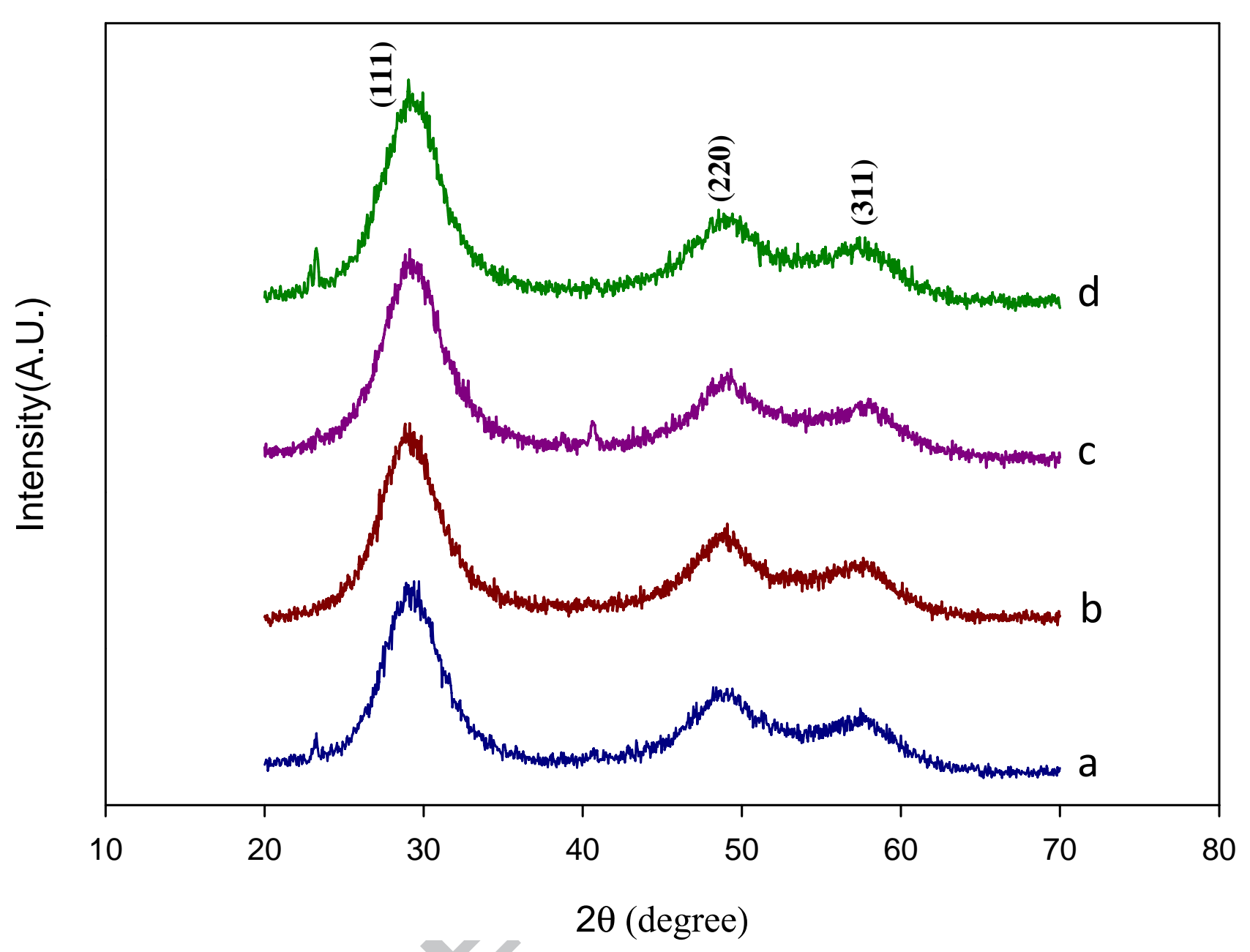

Fig. 2 


\section{ACCEPTED MANUSCRIPT}
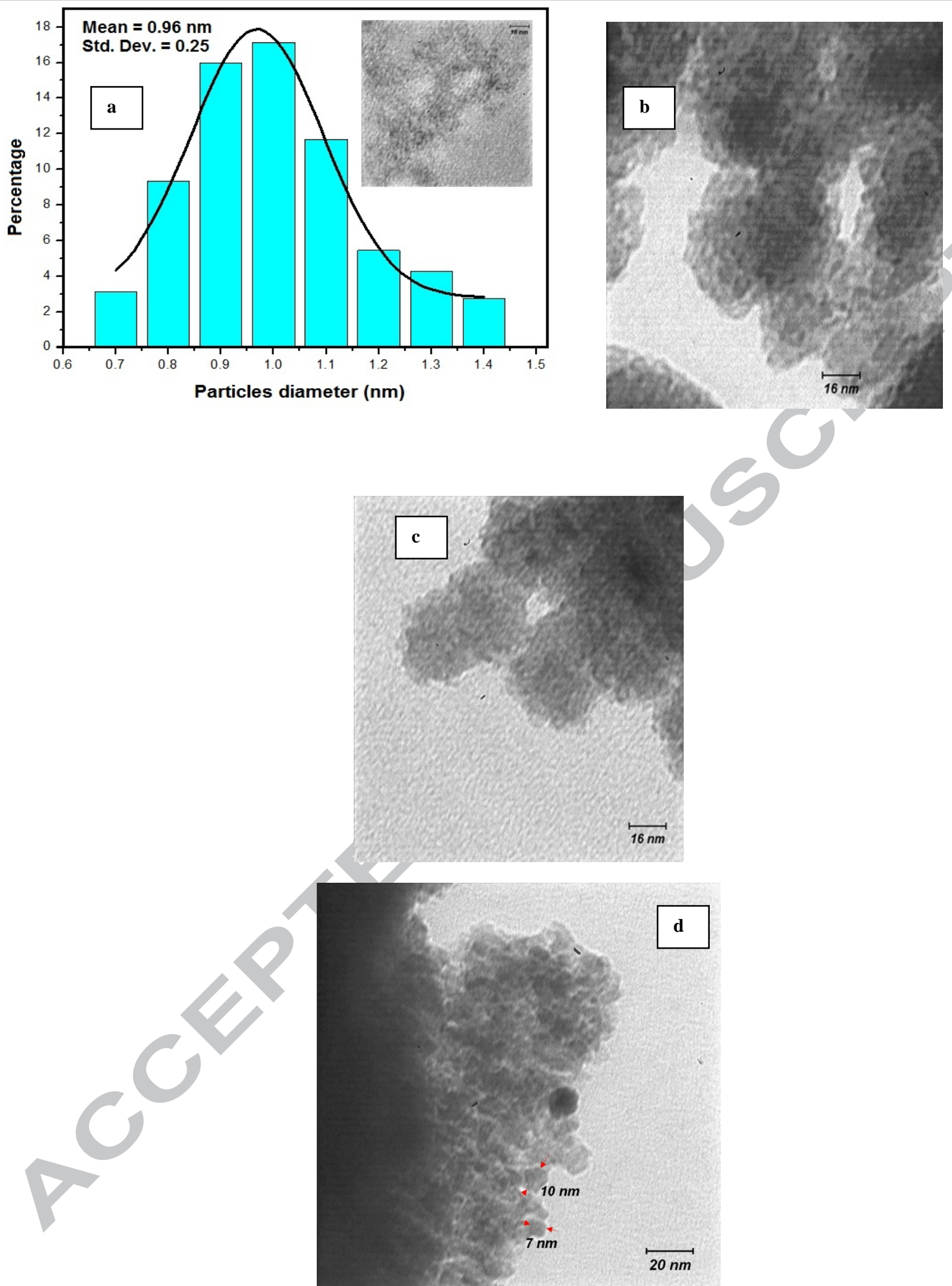

Fig. 3 
ACCEPTED MANUSCRIPT
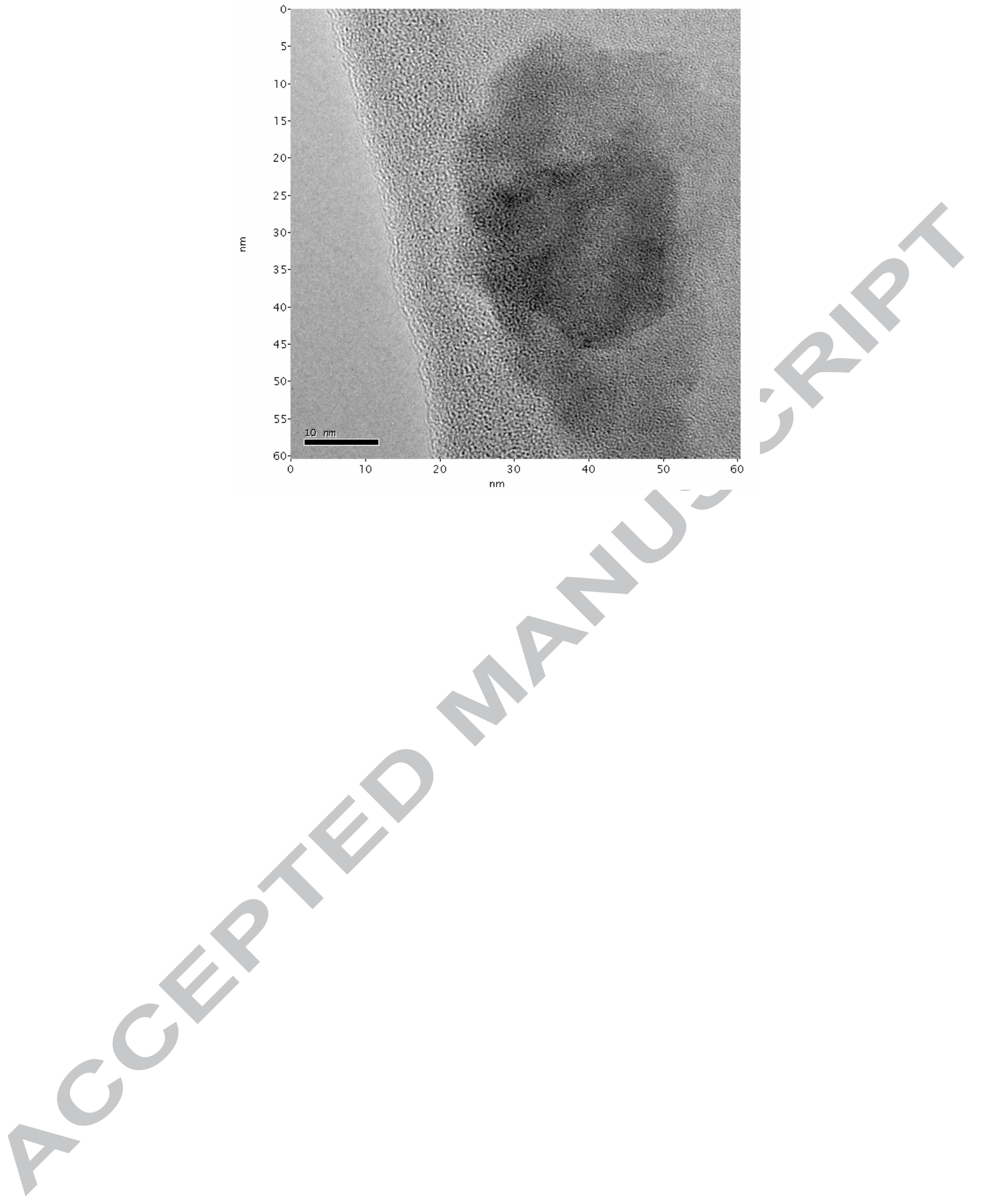

Fig. 4 


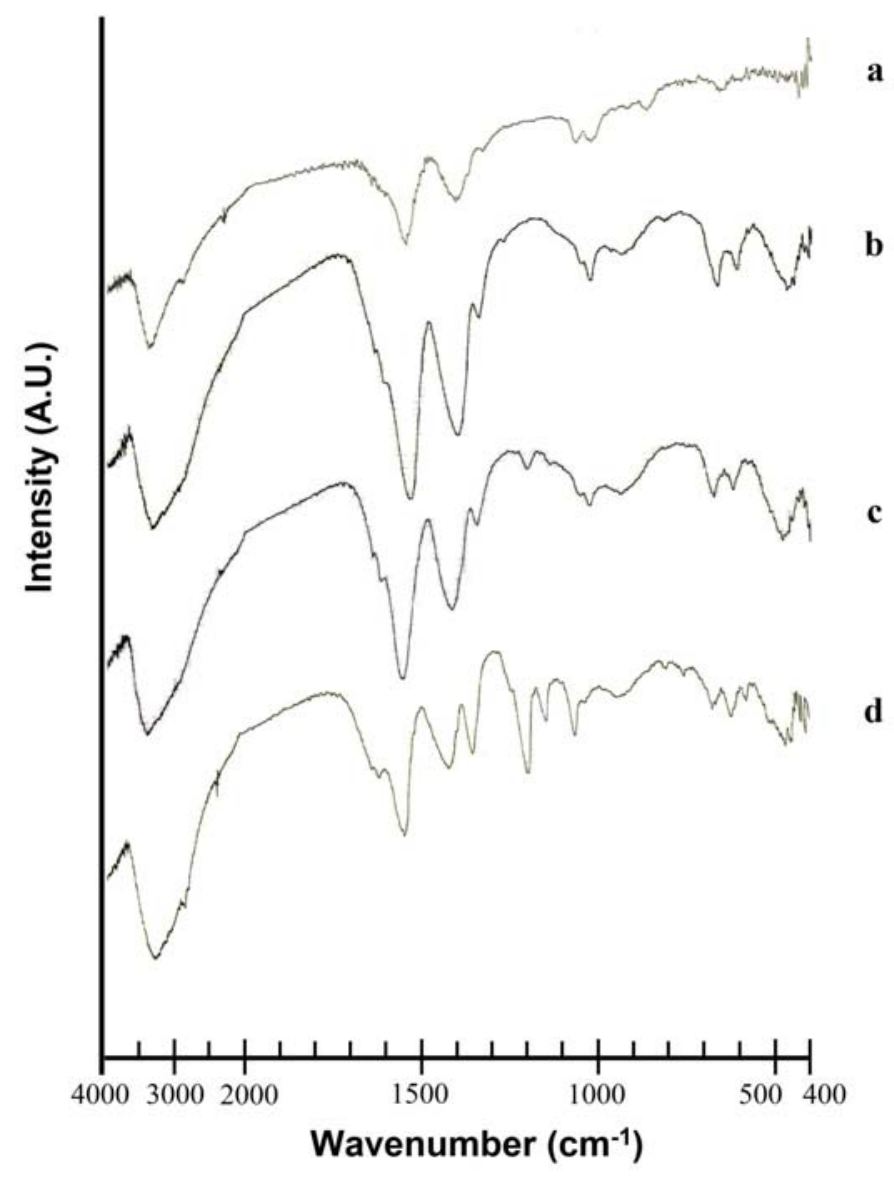

Fig. 5 


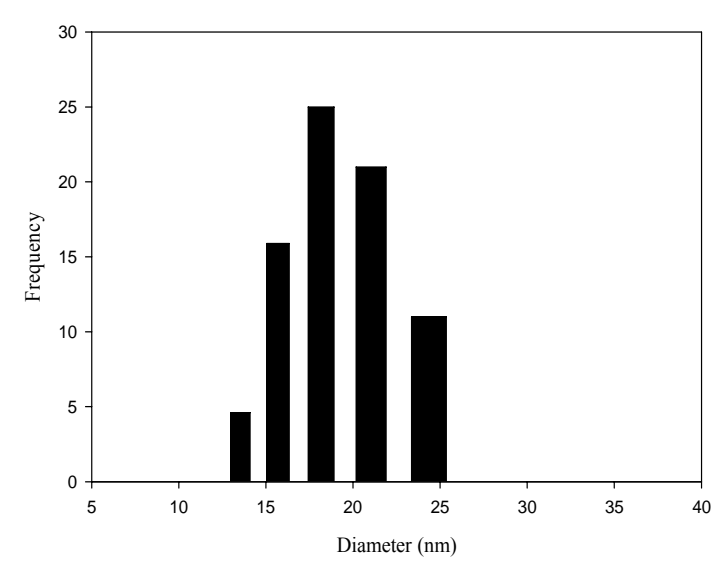

(a)

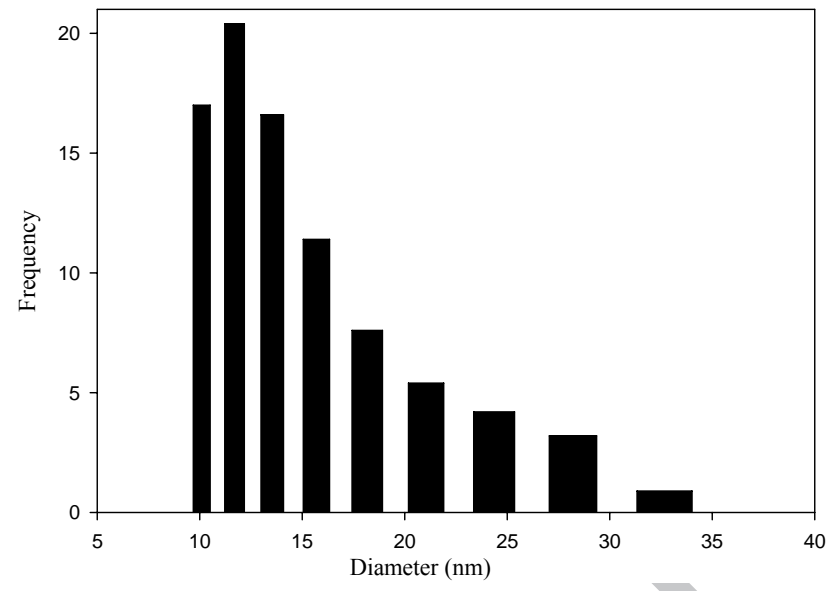

(b) 
Fig. 6

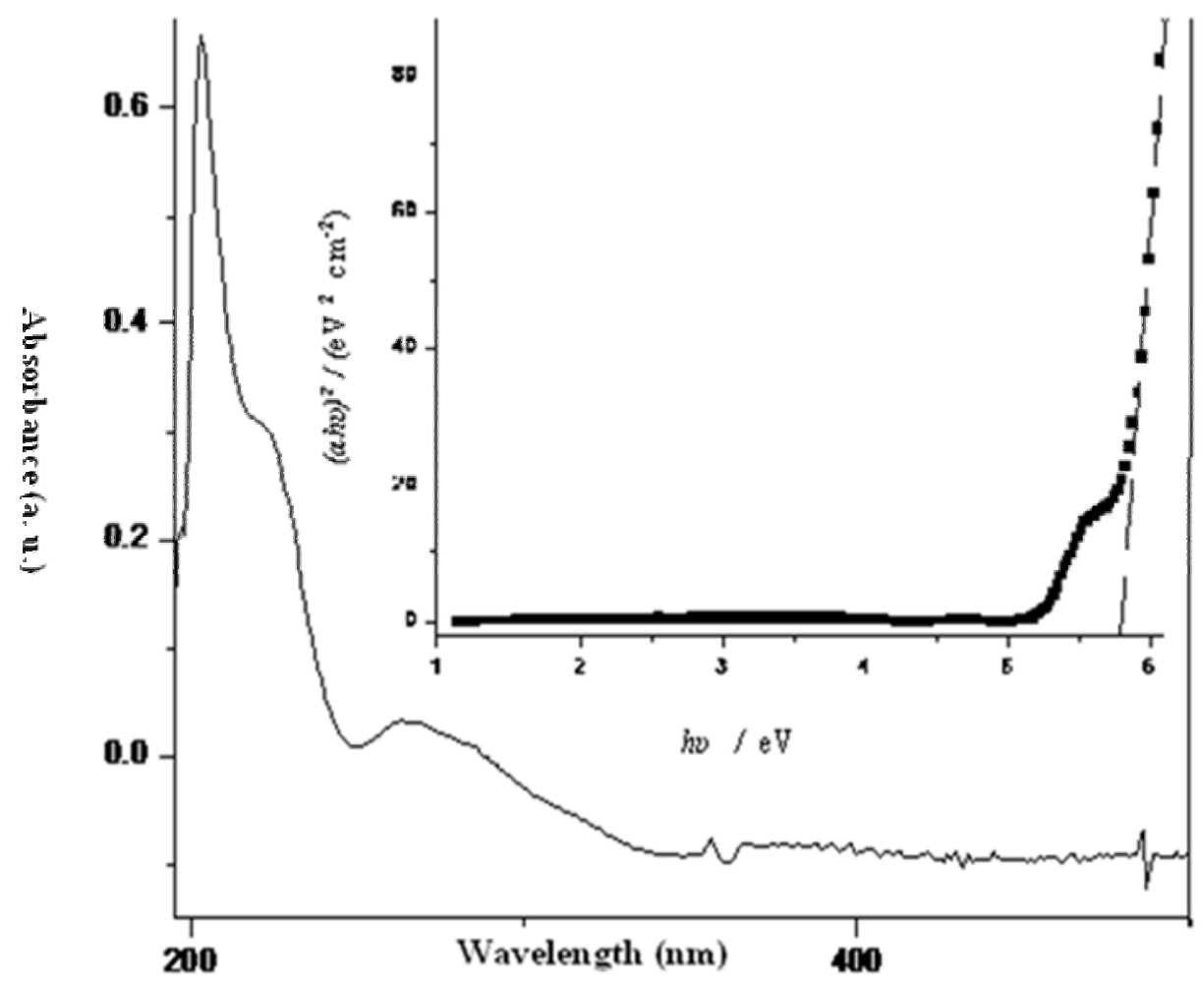


Wide band gap ZnS NPs were prepared which can be used in the photonic devices.

- Ionic liquids based on the imidazolium cation were used for the synthesis of ZnS NPs.

- The method is found to be convenient and environmentally friendly.

- No surfactant was used in the synthesis of ZnS NPs. 